Check for updates

Cite this: RSC Adv., 2017, 7, 35525

Received 14th June 2017

Accepted 4th July 2017

DOI: $10.1039 / \mathrm{c} 7 \mathrm{ra0} 6645 \mathrm{~g}$

rsc.li/rsc-advances

\section{Alq3 (tris(8-hydroxyquinolinato)aluminium) as a selective $n$-type contact for FAMAPIBr perovskite solar cells with efficient energy transfer to increase the solar cell photocurrent $\uparrow$}

\author{
Maria Méndez $\left(\mathbb{D}^{a}\right.$ and Emilio Palomares (D) *ab \\ We investigated the use of tris(8-hydroxyquinolinato)aluminium, known as Alq3, as a selective contact for \\ electrons in functional FAMAPIBr (formamidinium/methylammonium lead iodide bromide) solar cells. The \\ solar cells with Alq3 interfacial layers show excellent photocurrent upon standard 1 sun illumination (100 \\ $\mathrm{mW} \mathrm{cm}{ }^{-2}$ (1.5 AM G sun simulated light) due to efficient energy transfer from the selective contact layer \\ to the perovskite.
}

Solar cells based on solution processed perovskite materials are currently receiving much attention due to their rapid preparation, and light-to-energy conversion efficiencies as high as $22.1 \%^{1,2}$ under standard measurement conditions have been reported.

Much of the progress has been possible through composition tuning of the perovskite..$^{3,4}$ One of the highest and most stable perovskite solar cells uses a combination of formamidinium and methylammonium cations (Fig. 1). Yet, the exploration of suitable selective contacts, either n-type or p-type, is less investigated and often, despite changing the perovskite, the contacts remain the same. ${ }^{5}$

In this communication, we have prepared formamidinium/ methylammonium lead iodide bromide (FAMAPIBr) ${ }^{3,4,6}$ as photoactive semiconductor. Moreover, we have used a well-

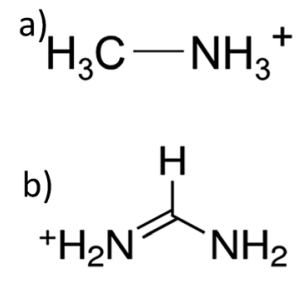

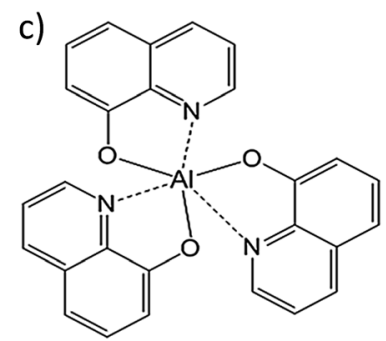

Fig. 1 Molecular structure for formamidinium (a), methylammonium (b) and Alq3 (c).

${ }^{a}$ The Institute of Chemical Research of Catalonia (ICIQ), The Barcelona Institute of Science and Technology (BIST), Avda. Països Catalans, 16, Tarragona, E-43007, Spain. E-mail: epalomares@iciq.es

${ }^{b}$ ICREA, Passeig Lluís Companys, 23, Barcelona, E-08010, Spain

$\dagger$ Electronic supplementary information (ESI) available: Experimental section and perovskite UV-Visible and TCSPC. See DOI: 10.1039/c7ra06645g known n-type material as interfacial layer and electron selective contact, the tris(8-hydroxyquinolinato)aluminium ${ }^{7,8}$ (Alq3 in Fig. 1). The deposition of Alq3, using thermal evaporation under high vacuum, allowed us to careful control the interfacial layer thickness between the compact $\mathrm{TiO}_{2}$ layer $\left(\mathrm{c}-\mathrm{TiO}_{2}\right)$ and the FAMAPIBr perovskite. The solar cells structure used was $\mathrm{FTO} / \mathrm{c}-$ $\mathrm{TiO}_{2} / \mathrm{Alq} 3 / \mathrm{FAMAPIBr} / \mathrm{spiro}-\mathrm{OMeTAD} / \mathrm{Ag}$, where FTO is fluorine doped tin oxide, the spiro-OMeTAD is the hole transport material (HTM) and $\mathrm{Ag}$ is silver metal.

In Table 1 we have listed the parameters for the different solar cells having different Alq3 thickness (see $\mathrm{S} 1 \uparrow$ for statistical data).

As can be seen, the best efficiencies were achieved with Alq3 thicknesses of $50 \mathrm{~nm}$. Interestingly, increasing the Alq3 thickness leads to better device photocurrents. Yet, the overall efficiency is similar to the standard cell due to the lower fill factor. The hysteresis effect on the measured $J V$ curves (forward/reverse sweeps) is also comparable. Fig. 2 illustrates the best $J V$ (current density $v s$. voltage) curves for the devices containing the Alq3 interfacial layer and the reference solar cell (forward/reverse sweeps).

Table 1 Summary of the best efficiencies obtained with different Alq3 thickness evaporated as interfacial layers

\begin{tabular}{lllllr}
\hline Device-ETL & Scan & $J_{\text {sc }}\left(\mathrm{mA} \mathrm{cm}^{-2}\right)$ & $V_{\text {oc }}(\mathrm{V})$ & FF & PCE (\%) \\
\hline $\mathrm{TiO}_{2}$-c/Alq3-10 nm & Fw & 23.0 & 0.775 & 0.43 & 7.71 \\
& Rev & 22.85 & 0.909 & 0.53 & 11.02 \\
$\mathrm{TiO}_{2}$-c/Alq3-25 nm & Fw & 22.45 & 0.853 & 0.44 & 8.51 \\
& Rev & 22.36 & 0.950 & 0.53 & 11.45 \\
$\mathrm{TiO}_{2}$-c/Alq3-50 nm & Fw & 24.93 & 0.793 & 0.41 & 8.13 \\
& Rev & 24.24 & 0.954 & 0.53 & 12.48 \\
Ref cell & Fw & 24.87 & 1.020 & 0.42 & 10.76 \\
& Rev & 24.30 & 1.065 & 0.53 & 13.83
\end{tabular}




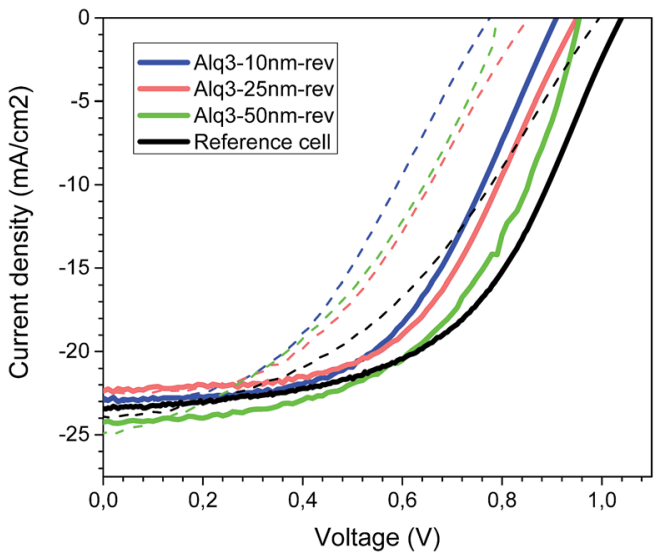

Fig. 2 The JV curves measured at 1 sun (1.5 AM G sun simulated light) under forward (dashed line) and reverse (solid line) bias.

We would like to point out that in both type of solar cells we observed the hysteresis phenomena, which has been recently associated to the accumulation of ionic species and the cell voltage. ${ }^{9}$ We carried out PIT-PV (Photo Induced Transient Photo-Voltage) measurements that consist on measuring photovoltage transient upon a short perturbation of the equilibrated $V_{\text {oc. }}{ }^{10}$ As can be seen (Fig. 3), the PIT-PV decay results are almost identical for the different solar cells, which implies that, in principle, there are not differences in the accumulation of charges at the interfaces and, moreover, in the carrier recombination kinetics.

To understand if the presence of the interfacial Alq3 layer effects a change over the accumulation of ionic charges at the interface between the perovskite and the Alq3 surface we measured PICE (Photo-Induced Charge Extraction) and PIDC (Photo-Induced Differential Charging). Although both experiments allow the estimation of the accumulated charge at the device under illumination, ${ }^{11,12}$ the main difference is that PIDC allows measuring the accumulated charge when the PICE decay is much slower than the carrier recombination lifetime and, thus, carriers can recombine before extracted. We have previously shown that, for example, in MAPI (methylammonium lead

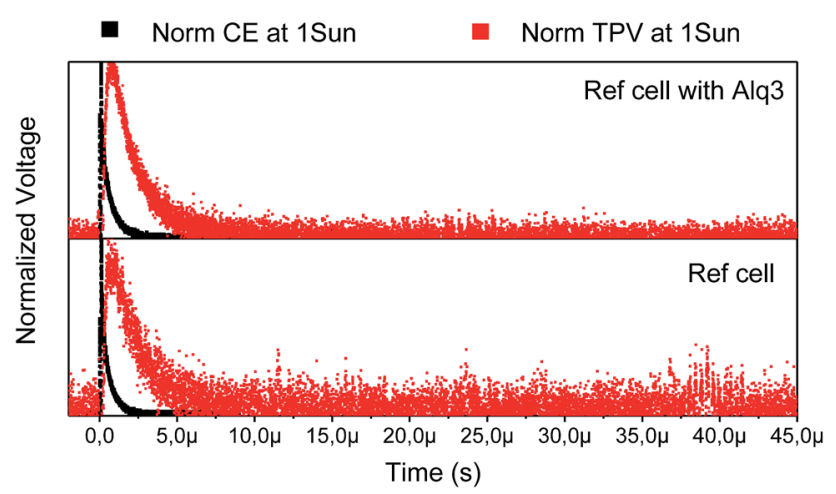

Fig. 3 Comparison between PICE (black square) and PIT-PV (red square) decays at 1 sun for perovskite solar cells with $\mathrm{c}-\mathrm{TiO}_{2}$ (bottom) and $\mathrm{c}-\mathrm{TiO}_{2} / \mathrm{Alq3}$ (top) as selective contacts.

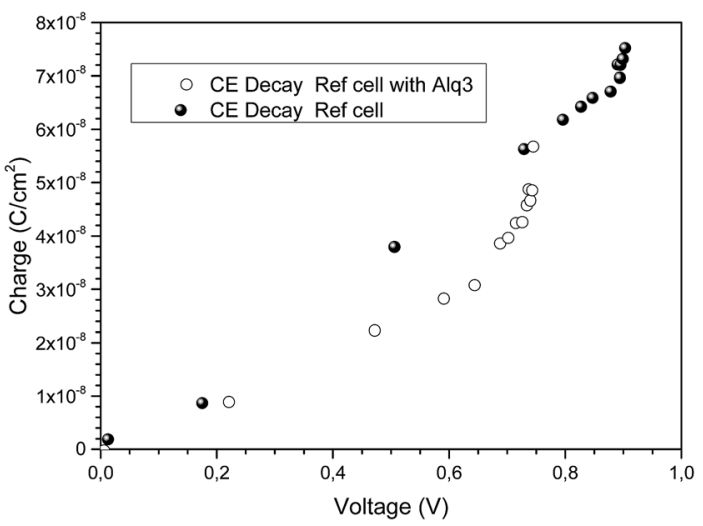

Fig. 4 Measured charge accumulated at the $\mathrm{c}-\mathrm{TiO}_{2}$ and $\mathrm{c}-\mathrm{TiO}_{2} / \mathrm{Alq} 3 /$ FAMAPIBr perovskite solar cells under different light bias.

iodide) perovskite solar cells both measurements lead to considerable differences for charges measured..$^{13}$

As shown in Fig. 4 the measured charge is alike on both types of devices.

Indeed, it seems evident that the presence of the Alq3 layer does not affects the extraction of charges and, in fact, in all cases the charge extraction was much faster than the PIT-PV (Fig. 3).

Once we have evaluated the transient photo-voltage and the charge extraction processes in the solar cells containing the interfacial layer of Alq3 and the reference cell we turned onto the differences observed in photocurrent. As listed in Table 1, the increase in Alq3 thickness leads to an increase in photocurrent.

We measured the absorption and fluorescence emission of an Alq3 film (Fig. 5). As shown in Fig. 5 (top), the emission of Alq3 overlaps with the FAMAPIBr absorption (Fig. S2 $\dagger$ ), which in principle will favour efficient energy transfer from the Alq3 to the perovskite. The normalized EQE measurements showed an increase in the incident photon-to-electron conversion efficiency in the region between 400 to $600 \mathrm{~nm}$ corresponding to the absorption and emission regions of Alq3 (Fig. 5 bottom). Hence, we postulate that the increase in device photocurrent is due to efficient energy transfer between the Alq3 thin film and

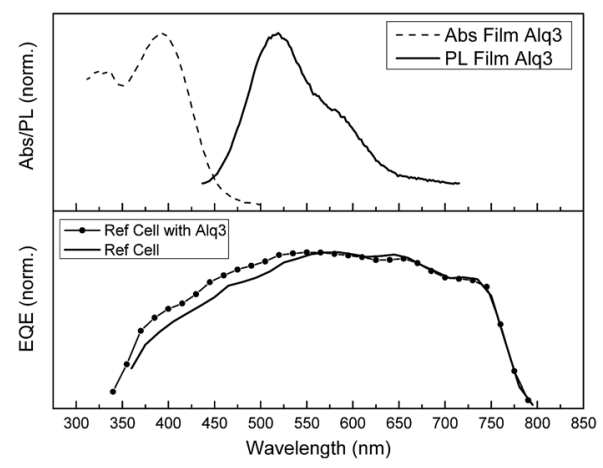

Fig. 5 The absorption and fluorescence emission for a thick film of Alq3 deposited on glass (top) and the normalised EQE spectra for two FAMAPIBr containing Alq3 and $\mathrm{c}-\mathrm{TiO}_{2}$ as selective contacts (bottom). 

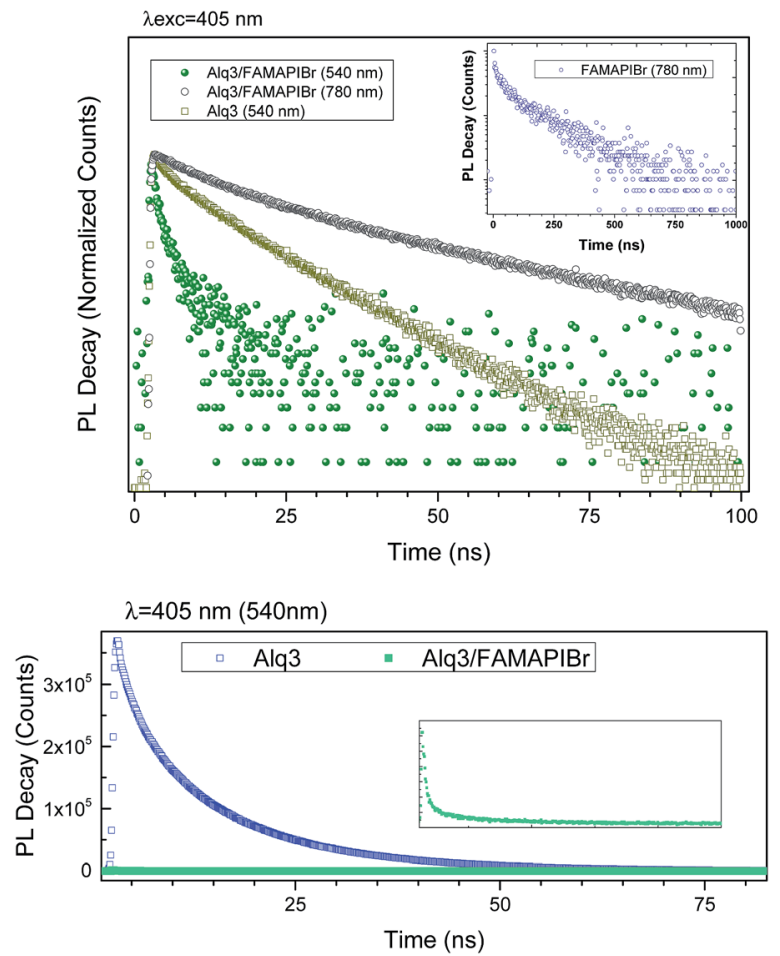

Fig. 6 The PL decays for a film of FAMAPIBr, Alq3 and Alq3/FAMAPIBr (top), and the PL decays for a film of Alq3 and Alq3/FAMAPIBr measured with a fixed acquisition time (bottom, the inset corresponds to the Alq3/FMAPIBr). All the films were excited at $405 \mathrm{~nm}$, monitored either at 540 or $780 \mathrm{~nm}$, and illuminated through the Alq3 layer, except the FAMAPIBr film.

the FAMAPIBr perovskite. To further ascertain the energy transfer process we carried out photoluminescence emission lifetime measurements. As can be seen, the emission lifetime and the signal amplitude changes for the Alq3 film when used as selective contact (Fig. 6).

The Alq3 thin film has an emission maximum at $540 \mathrm{~nm}$ when excited at $405 \mathrm{~nm}$. The measured Alq3 thin film fluorescence lifetime is of $\tau=10.7 \mathrm{~ns}$. In contrast, the emission of the perovskite at the same excitation wavelength $(405 \mathrm{~nm})$ but monitoring at $780 \mathrm{~nm}$ is of $\tau=0.1 \mu \mathrm{s}$ (S3† shows the perovskite PL emission). When both layers are in contact, the emission lifetime for the former is reduced to $\tau=1.7 \mathrm{~ns}$ and also the emission of the later is reduced to $\tau=19.9 \mathrm{~ns}$. In the case of the Alq3 contact is due to the efficient energy transfer to the perovskite while in the case of the perovskite is due to the efficient charge injection into the Alq3. Furthermore, measuring the fluorescence lifetime at the same acquisition time for the Alq3/ perovskite thin film and comparing to a standard Alq3 thin film it is clear that the emission is quenched almost at $100 \%$ due to the energy transfer to the perovskite (Fig. 6 bottom).

In conclusion, we have studied Alq3 as selective contact for electrons in FAMAPIBr perovskite solar cells. The decrease in photovoltage for the $\mathrm{FTO} / \mathrm{c}_{-} \mathrm{TiO}_{2} / \mathrm{Alq} 3 / \mathrm{FAMAPIBr} /$ spiro OMeTAD/Ag is not significant. Studies in depth of the factors that affect the $V_{\mathrm{oc}}$ namely, charge accumulation and carrier recombination lifetime also show that there are not remarkable differences. The measurement of the luminescence emission in Alq3 films and the EQE spectra of the different solar cells lead us to conclude that the increase in photocurrent is due to an efficient energy transfer process between the Alq3 interfacial layer and the perovskite film. Further efforts to increase the fill factor in these solar cells having the Alq3 interfacial layer are being carried out to achieve higher efficiencies through efficient energy transfer from the selective contact.

\section{Acknowledgements}

The authors would like to acknowledge ICIQ-BIST (Severo Ochoa Excellence Accreditation 2014-2018 SEV-2013-0319) and ICREA for economical support. E. P. is also grateful to Spanish MINECO for the CTQ2016-80042-R project, Generalitat de Catalunya for the AGAUR funding and finally to the COFUND European Commission for the COFUND programme (ICIQ-IPMP).

\section{References}

1 M. A. Green, K. Emery, Y. Hishikawa, W. Warta, E. D. Dunlop, D. H. Levi and A. W. Y. Ho-Baillie, Progress in Photovoltaics: Research and Applications, 2017, 25, 3-13.

2 https://www.nrel.gov.

3 N. J. Jeon, J. H. Noh, W. S. Yang, Y. C. Kim, S. Ryu, J. Seo and S. I. Seok, Nature, 2015, 517, 476-480.

4 D. Bi, W. Tress, M. I. Dar, P. Gao, J. Luo, C. Renevier, K. Schenk, A. Abate, F. Giordano, J.-P. Correa Baena, J.-D. Decoppet, S. M. Zakeeruddin, M. K. Nazeeruddin, M. Grätzel and A. Hagfeldt, Sci. Adv., 2016, 2, 1-7.

5 S. Ameen, M. A. Rub, S. A. Kosa, K. A. Alamry, M. S. Akhtar, H.-S. Shin, H.-K. Seo, A. M. Asiri and M. K. Nazeeruddin, ChemSusChem, 2016, 9, 10-27.

6 N. Pellet, P. Gao, G. Gregori, T.-Y. Yang, M. K. Nazeeruddin, J. Maier and M. Grätzel, Angew. Chem., Int. Ed., 2014, 53, 3151-3157.

7 X. Ma, G. K. Lim, K. D. M. Harris, D. C. Apperley, P. N. Horton, M. B. Hursthouse and S. L. James, Cryst. Growth Des., 2012, 12, 5869-5872.

8 L. Yao, L. Li, L. Qin, Y. Ma, W. Wang, H. Meng, W. Jin, Y. Wang, W. Xu, G. Ran, L. You and G. Qin, Nanotechnology, 2017, 28, 105201-105211.

9 S. Ravishankar, O. Almora, C. Echeverría-Arrondo, E. Ghahremanirad, C. Aranda, A. Guerrero, F. FabregatSantiago, A. Zaban, G. Garcia-Belmonte and J. Bisquert, J. Phys. Chem. Lett., 2017, 8, 915-921.

10 J. M. Marin-Beloqui, L. Lanzetta and E. Palomares, Chem. Mater., 2016, 28, 207-213.

11 B. C. O'Regan, P. R. F. Burnes, X. Li, C. Law, E. Palomares and J. M. Marin-Beloqui, J. Am. Chem. Soc., 2015, 137, 5087-5099.

12 L. Cabau, I. Garcia-Benito, A. Molina-Ontoria, N. F. Montcada, N. Martin, A. Vidal-Ferran and E. Palomares, Chem. Commun., 2015, 51, 13980-13982.

13 N. F. Montcada, J. M. Marín-Beloqui, W. Cambarau, J. Jiménez-López, L. Cabau, K. T. Cho, M. K. Nazeeruddin and E. Palomares, ACS Energy Lett., 2017, 2, 182-187. 